SF

524

. 52

CE

F>5

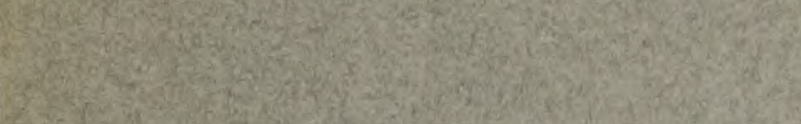

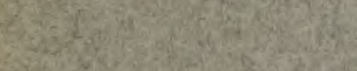

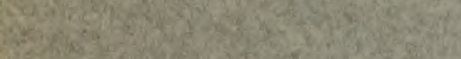

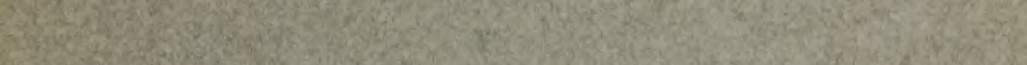

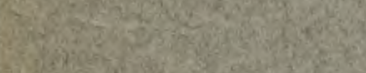

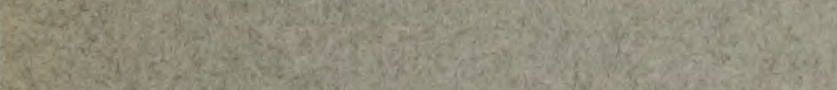

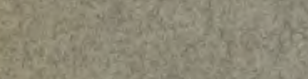

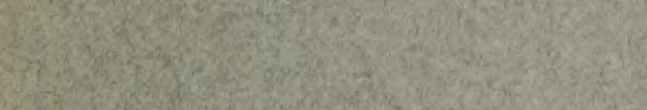

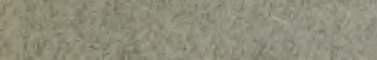




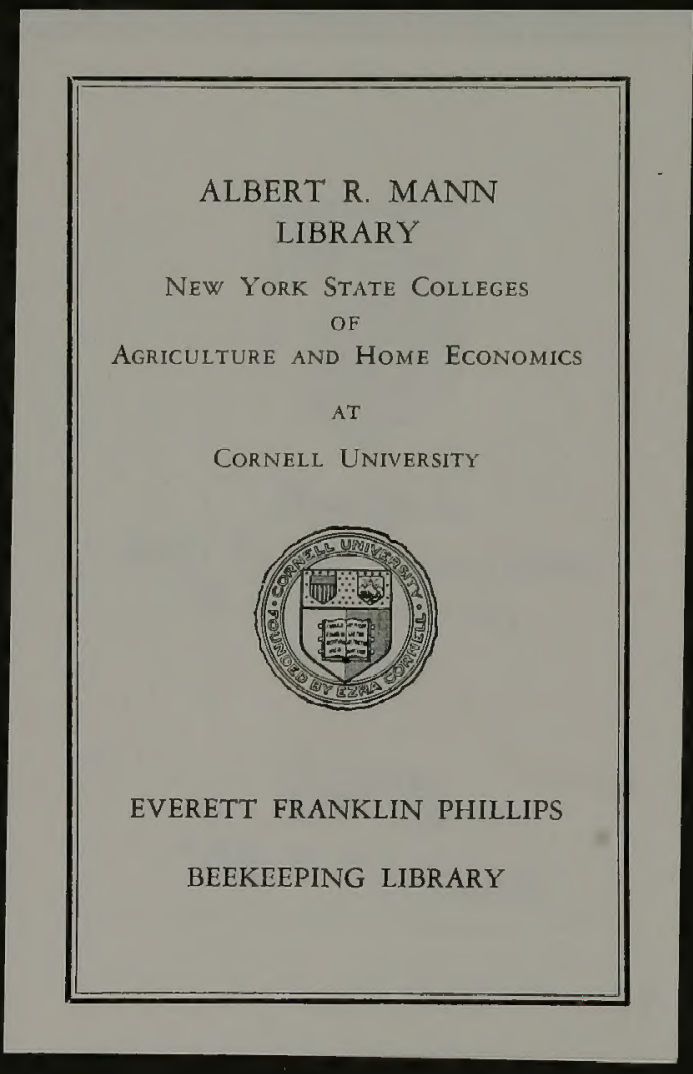




\section{Colorado Apiary Inspection}

\section{BY WESLEY FOSTER}

Deputy Bee Inspector

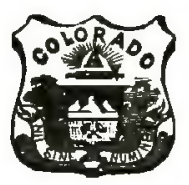




$$
\begin{aligned}
& \text { SF } \\
& 524 \\
& .52 \\
& C 6 \\
& F 75
\end{aligned}
$$

\section{OFFICIAL STAFF}

ClaRENCE P. GILlETtE.................... State Entomologist GEORGE M. LIST .................. Deputy State Entomologist WESLEY FOSTER...................... Deputy, Bee Inspector WILLIAM L. BURNETT.............. Deputy, Rodent Investigations 


\section{COLORADO APIARY INSPECTION}

BY WESLEY FOSTER, BOULDER, colorado

The beekeeping industry, while one of the minor branches of agriculture, assumes proportions in Colorado of commercial importance in all the irrigated districts. Bees are kept on something 'over five thousand farms, and over one hundred thousand colonies make up the apiary population of the state. The value of honey, wax, and hive products totals over half a million dollars a year. The honey industry is one of conservation. If the nectar of the flowers is not gathered by the bees, it is lost. The outlay for supplies is less than in most lines of production, so that the net wealth production from beekeeping is greater than appears in the figures. The value of bees in the cross-pollination of fruit blossoms is very great and can hardly be estimated in dollars and cents.

The honey resources of Colorado have not been fully developed for two main reasons. First, the ravages of American foul-brood have decimated the number of colonies of bees in many counties of the state. There are few important honey-producing districts where foul-brood is not a menace to the life and profits of the industry.

The second main reason for the tardy development of the industry is the heavy winter losses sustained every few years. Winter losses in Colorado are caused by lack of protection given the colonies during the winter, practically all colonies being wintered in single-walled hives on their summer stands, and a poor quality of honey stored in the hives for the winter supply.

With a more general understanding and practice of the best beekeeping methods, losses from foul-brood and wintering would not be so common.

It is the experience of all practical beekeepers that, after combating foul-brood for a few years, it loses its terrors for them. Its rapid spread and quick destruction of whole colonies and apiaries cause those who encounter the disease for the first time considerable alarm, but, after treating the disease and curing it in many colonies, the beekeeper soon realizes that, with watchfulness, he is easily master of the situation.

This situation has led many beekeepers and inspectors to the opinion that foul-brood is a blessing in disguise, because it eliminates the careless beekeeper and is not a terror to the experienced operator. American foul-brood responds to treatment in a satisfactory manner, and serious concern need not be felt by anyone who will follow the instructions given by the inspectors, or directions found in bee journals and publications on bee culture.

It is practically impossible to rid a district entirely of disease, but it is easy so to reduce the percentage of foul-brood that there is very little loss each year.

\section{APIARY INSPECTION IS EDUCATIONAL}

The work of apiary inspection is, first, one of instruction in the nature of bee diseases, their detection and cure. The inspector who is thoroughly competent and conversant with his duties will so help and instruct the beekeepers that a large proportion of them can be their own inspectors.

Next in importance of an inspector's duties should be using his thorough knowledge of the spread of disease over the county so as to prevent the further distribution of the infection by indiscriminate moving of diseased apiaries. It is necessary to have a permit from the inspector before moving or shipping an apiary. If it is desired to move an apiary, application for a permit must be made to the inspector, who will examine the apiary and, if found free of disease, issue a permit, unless special quarantine regulations have been adopted in the districts affected, which would preclude issuance of a permit at the time of the first examination. 
THE INSPECTOR'S PROCEDURE

When foul-brood is found in an apiary, each colony is to be examined by the inspector and all diseased colonies marked, and the owner or caretaker given instructions for curing the diseased bees and disinfecting all other beekeeping material that might spread the disease. The inspector is then authorized by the law to inspect the other apiaries in the vicinity, to ascertain the extent to which the disease may be spread. If the inspection work is thoroughly done, and a second inspection made ten days to two weeks after the first one, to see that all diseased colonies have been treated, foul-brood may be reduced in percentage quite rapidly. Any diseased colonies or apiary appliances from which bees may be robbing infected honey should be burned or buried at once by the inspector. The beekeeper who is so careless as to allow the robbing of diseased hives in his yard will hardly be careful enough, in rendering diseased material, to prevent further spreading of the disease when doing this work.

\section{BEEKEEPERS' AID TO THE INSPECTOR}

The work of the county inspector can be greatly aided by the beekeepers themselves through information, suggestions, and advice. If the majority of the beekeepers are not supporters of the inspection work, the results secured will be insignificant. The inspection work can be aided in no better way than through the organization of county beekeepers' clubs or associations. County beekeepers' clubs are generally organized for some or all of the following things: to secure the support of the inspection work by the county commissioners; to offer advice and suggestions to the inspector as to the prosecution of his work; to maintain a uniform price on honey; to club orders for bee supplies; to promote the educational and social interests of the members, etc.

One feature that is especially helpful to the inspector is for each member to furnish the inspector with the number and location of his colonies, and the names and location of all his neighboring beekeepers, in order that the inspector may have as complete a list as possible of all the beekeepers in the county.

\section{FALL AND WINTER INSPECTION OF BEES}

Spring and early summer is the season for the inspector to do the bulk of his work. But cases arise when it is important to do some inspection at other seasons of the year. If, as often happens, the inspector does not have time or opportunity to inspect all the bees in the spring and early summer, a superficial fall inspection of these apiaries will give him an opportunity to find dead or dying diseased colonies, and to destroy them before robbing has spread the disease farther.

A colony affectel with foul-brood in the fall is very ilkely to die during the winter, and, if not attended to when found, will spread the disease.

A bee tent may prove of value to the inspector in doing some of the necessary fall inspection, if the bees are inclined to rob. In small apiaries, of not over a dozen hives, robbing will hardly be induced, as the inspection is soon done; but in larger apiaries a tent is a necessity, if the inspection has to be done.

In winter inspection the hives should not be opened unless the day is warm and the bees are flying. It is easy to find the diseased colonies that would spread the disease, if there are any, without opening the hives and disturbing the bees. 
WILD BEES IN TREES, ROCKS, AND BULLDINGS

Objection to the spending of county funds for inspection work has been made at times on account of the presence of bees in the woods, crevices in the rocks, between the walls of buildings, etc. The argument is put forward that, unless the bees are cleaned out of these places, foul-brood will never be eradicated. It is true that bees in these places are a menace, but their number is so small, in comparison with the bees in hives, that it has been found to be a negligible influence. Where the inspection work has been carried on thoroughly, foul-brood has been reduced to the minimum in spite of the wild bees.

Bees in buildings may be removed, or the holes through which they gain access stopped up; and the same may be done with bee trees, if such are easily accessible.

\section{THE COUNTY WITH NO INSPECTOR}

In case there is no inspector in your county, or he is not available when most needed, you can still make beekeeping profitable, so far as disease is concerned. If you fully understand the treatment of foulbrood, you will keep your own apiary thoroughly inspected and clean. and by helping your neighbors care for their bees, or by buying them out, you can keep foul-brood at a safe distance from your own apiary. It is cheaper in these cases to do considerable work gratuitously than to have one's colonies continually reinfected.

\section{COLORADO COUNTY APIARY INSPECTORS FOR THE YEAR 1914}

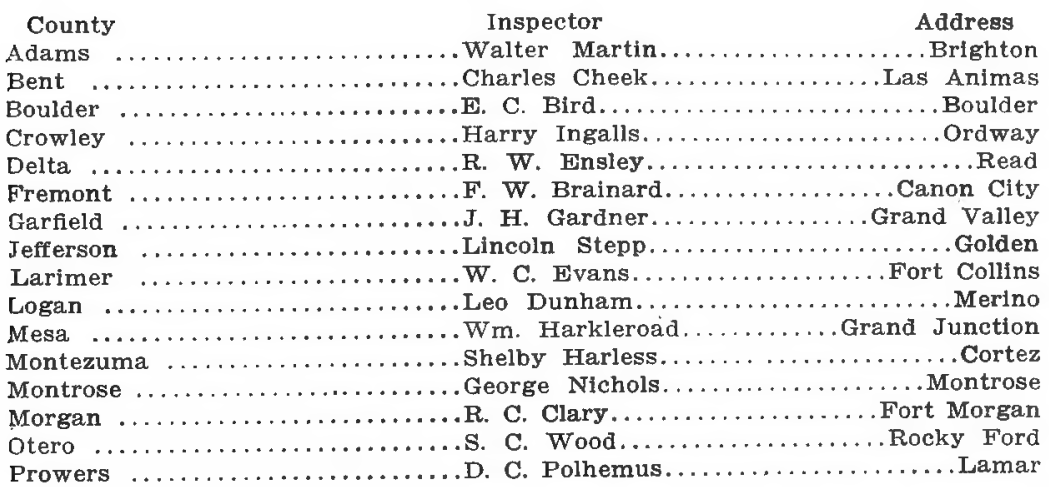




\title{
APIARY INSPECTION.
}

\author{
(S. B. No. 169, by Senator Tobin and Mr. Skinner.)
}

\section{AN ACT}

TO ESTABLISH A DIVISION OF APIARY INSPECTION AND INVISTIGATION UNDER THE STATE ENTOMOLOGIST; TO PROVIDE FOR INVESTIGATIONS IN BEE CULTURE AND THE INSPECTION OF BEES FOR CONTAGIOUS DISEASES; TO PRO VIDE FOR THE PREVENTION AND SPREAD OF BEE DISEASES; TO PROVIDE FOR COUNTY APICULTURAL INSPECTORS, TO PROVIDE FOR THE TRANSFER OF BEES FROM BOX HIVES : TO PROVIDE FOR THE PREVENTION OF THE POISONING OF BEES BY FRUIT TREE SPRAYS; TO PROVIDE PENALTIES FOR VIOLATIONS OF THE PROVISIONS OF THIS ACT; TO MAKE AN APPROPRIATION FOR CARRYING OUT THIS ACT, AND TO REPEAL ALL ACTS AND PARTS OF ACTS IN CONFLICT WITH THIS ACT.

Be It Enacted by the General Assembly of the state of Colorado:

\section{State Entomologist to inspect, deputies.}

Section 1. The State Entomologist is hereby authorized to conduct a division of apiary investigation and of inspection of bee diseases directly or through a deputy, who is experienced in apiculture, the investigation to cover the introduction of nectar producing plants, the agencies influencing the secretion of nectar in plants, and such other objects as may advance bee culture in Colorado. The inspection shall extend to all parts of the State where bees are kept, for the prevention, eradication or control of bee diseases.

\section{County Apicultural Inspectors.}

Section 2. The persons employed under this act, aside from the State Entomologist and his deputy in charge of apiculture, shall be the County Apicultural Inspectors, whose duties it shall be to carry out the provisions of this act, Assistant Apicultural Inspectors working under the general direction of the County Apicultural Inspectors, when necessary, and engaged by the Apicultural Inspectors, with the consent of the County Commissioners; and helpers who shall be common laborers employed to aid in carrying out the provisions of this act.

\section{County Commissioners appoint.}

Section 3. The County Commissioners of any county, when petitioned by not less than fifteen bee keepers of their county to appoint an Apicultural Inspector, shall make such appointment as soon as possible.

\section{State Entomologist to examine.}

It shall be the duty of the State Entomologist to examine all persons appointed by the County Commissioners as Apicultural Inspectors, and if found competent and fully qualified to perform the duties of the office he shall issue to such applicant a license as a County Apicultural Inspector; which license shall certify to the competency of such applicant and shall authorize him to act as County Apicultural Inspector for a period of one year or until his successor has qualified. 


\section{Notify Entomologist of foul brood.}

Section 4. Every bee keeper or other person who shall be aware of the existence of foul brood, or any other infectious or contagious disease of bees, either in his own apiary or elsewhere in the State, shall immediately notify the State Entomologist, his deputy or the County Apicultural Inspector of the existence of such diseases.

\section{Notice, examinations.}

Section 5. The State Entomologist, his deputy in charge of apiculture, or the County Apicultural Inspector, shall, when notified in writing by the owner of an apiary or any bee keeper, examine any reported apiaries and if any contagious disease is present, examine all others in the same locality, not reported and ascertain whether or not any disease known as American Foul Brood, European Foul Brood, or any other disease which is infectious in its nature and injurious to honey bees. in their egg, larval, pupal, or adult stages, exists in such apiaries; and if satisfied of the existence of any such disease shall give the owner or caretaker of the diseased apiaries full written or printed instructions how to treat such cases as in his judgment seem best, and state a time in which his instructions shall be carried out.

\section{Destroy colonies not cured.}

Section 6. The State Entomologist, his deputy in charge of apiculture, or the county apicultural inspector may, if necessary, visit all diseased apiaries a second time, after ten days and if need be destroy all colonies of bees that he may find not cured of such disease, and all honey, combs, and appliances, which would spread disease, without recompense to the owner, lessee or agent thereof.

\section{Permit to move.}

Section 7. No person or persons, either as owner, agent, servant, employe, or common carrier, shall sell, barter or give away or move an apiary, bees, honey or bee keeping appliances wherein disease exists without a permit from the State Entomologist, his deputy in charge of apiculture, or the County Apicultural Inspector.

\section{Transfer from box to movable frame hives.}

Section 8. The State Entomologist, his deputies or apicultural inspectors shall have full power in their discretion to order any owner or possessor of bees dwelling in box hives (being hives without movable combs) to transfer such bees to movable frame hives within a specified time.

\section{Authorized to enter premises.}

Section 9. The State Entomologist, his deputy or an Apicultural Inspector having jurisdiction, together with such help as they may need in the prosecution of their work, are authorized during reasonable business hours, to enter upon or into any premises, land, buildings or places where bees or bee keeping appliances are kept, for carrying out the provisions of this act.

\section{Disinfection.}

Section 10. After inspecting infected hives or fixtures or handling diseased bees, the inspector or his assistants, shall before leaving the premises or proceeding to any other apiary, thoroughly disinfect any portion of their person and clothing and any tools and appliances used by them which have come in contact with infected material. 


\section{Unlawful spraying.}

Section 11. It shall be unlawful to spray fruit trees while in full bloom with any poisonous spray which is injurious to bees in their egg, larval or adult stages.

\section{Punishment by fine.}

Section 12. Each and every violation of any of the provisions of this act, and each and every non-compliance with the provisions thereof, or any of them, or non-compliance with any notice or direction given by the apicultural inspector in charge under the provisions of this act, shall be punishable by fine in the sum of not less than five nor more than one hundred dollars, and each and every day that any person, firm or corporation shall fail to comply with any notice in writing received from the State Entomologist, his deputy or apicultural inspector shall be deemed a separate offense.

\section{Salary and expenses of deputy.}

Section 13. The salary and expenses of the deputy in charge of apiculture in carrying out the provisions of this act shall be paid from the State Treasury, but the per diem and expenses of the County Apicultural Inspectors and their assistants shall be paid out of the treasuries of the counties where their work is performed in each case.

\section{Per diem of Inspectors.}

County Apicultural Inspectors shall receive four dollars $(\$ 4.00)$ a day and assistant inspectors three dollars and a half $(\$ 3.50)$ a day in addition to their actual and reasonable expenses for time actually spent in carrying out the provisions of this act.

\section{Appropriation.}

Section 14. The sum of one thousand five hundred dollars $(\$ 1,500)$ per annum is hereby appropriated to be expended for this work under the direction of the State Entomologist, to pay the salary of the deputy in charge of apiculture, the necessary expenses in traveling, printing blanks and circulars, and in otherwise carrying out the provisions of this act.

The State Auditor is hereby authorized to draw his warrants upon the State Treasurer for the sum herein appropriated upon the presentation of proper vouchers, and the treasurer shall pay the same out of any funds in the State Treasury, not otherwise appropriated.

\section{Repealing clause.}

Section 15. All acts or parts of acts in conflict with this act are hereby repealed.

Approved: May 2, 1913, at 8:09 o'clock P. M. 
Comelluniversity Library

Colorado apiary inspection,

31924003202839 


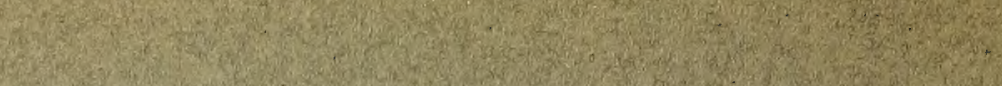

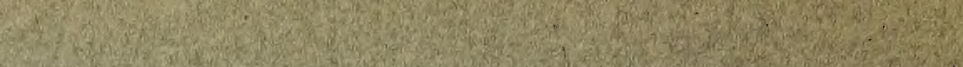

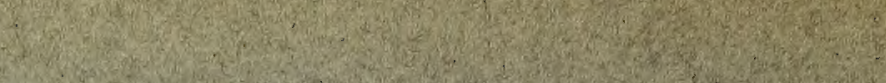

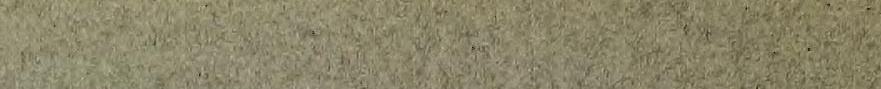
2.

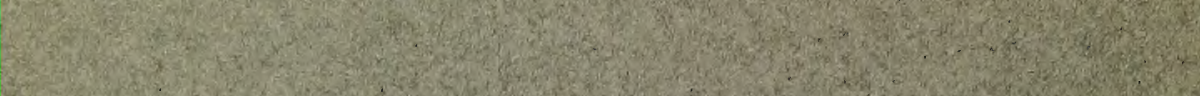

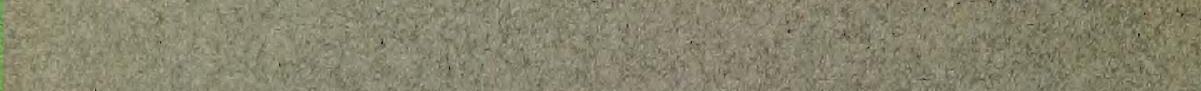

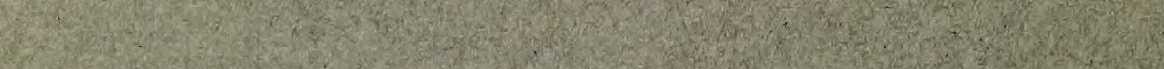
25. 27) 20.4.

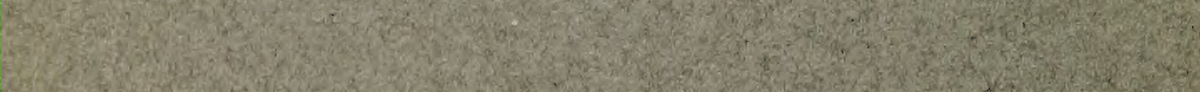

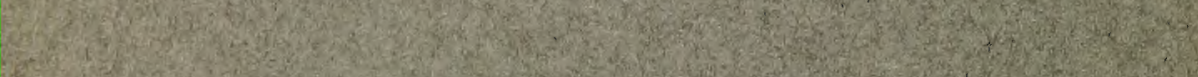
20 W.

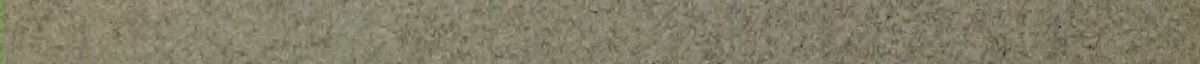

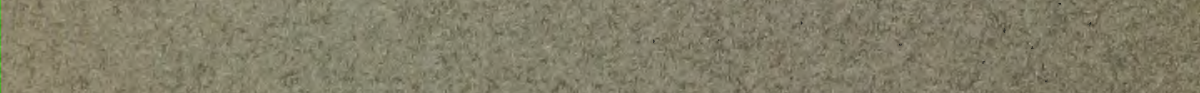

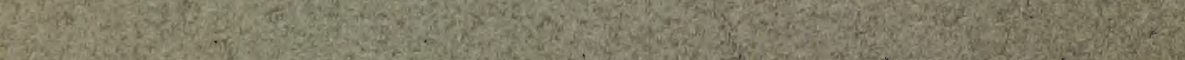

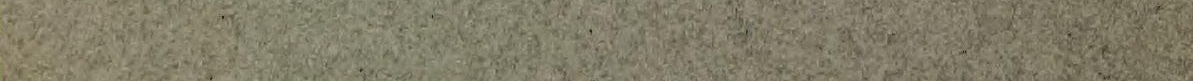

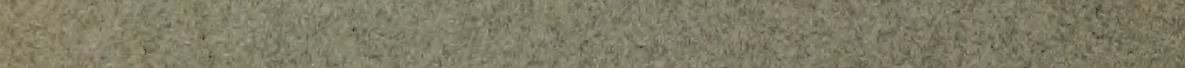
19. G3.

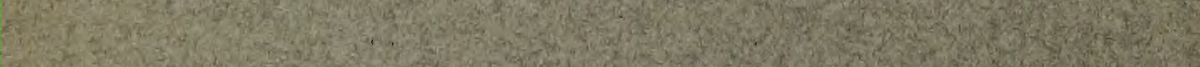

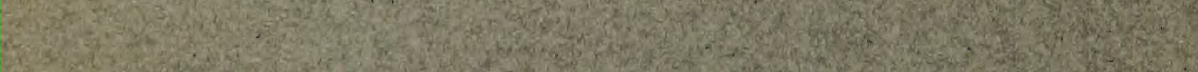

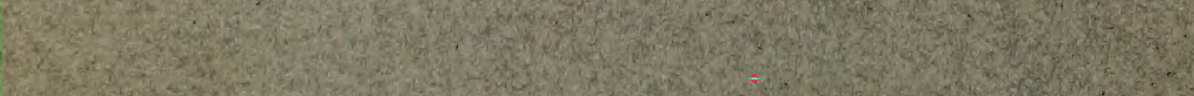

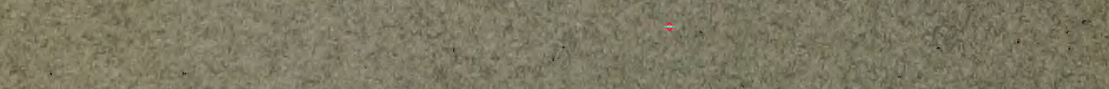

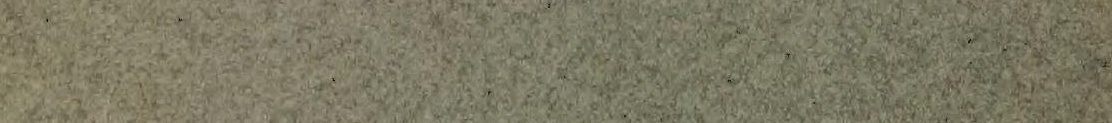
C.

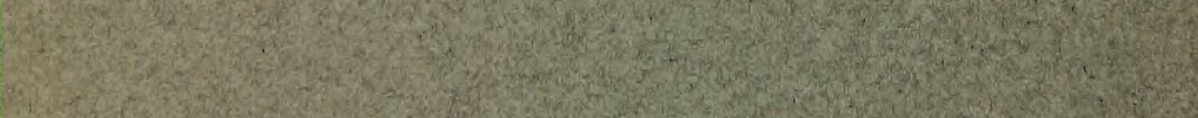

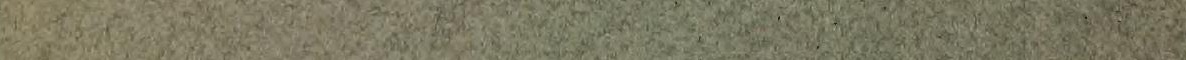

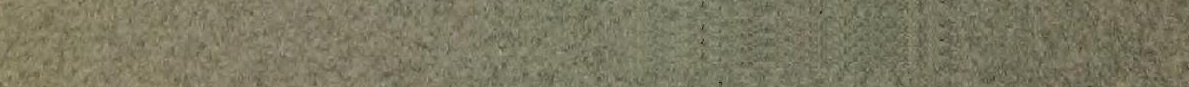

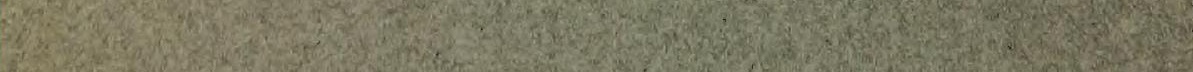

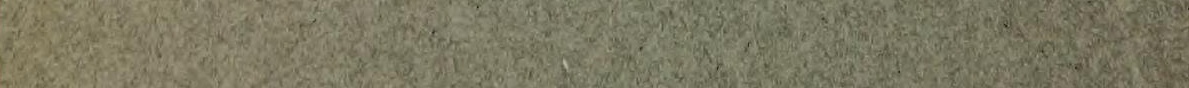

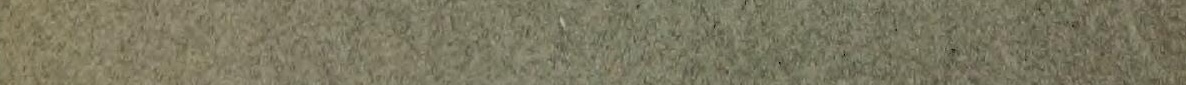
Hif

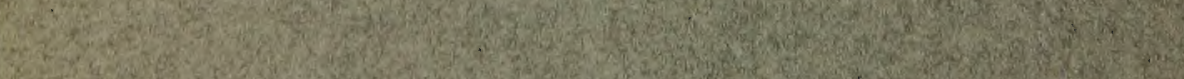

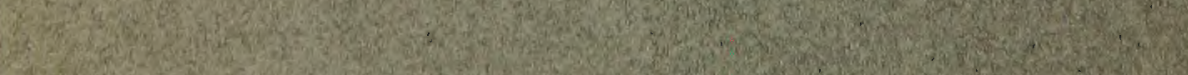

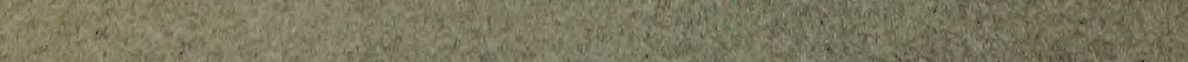

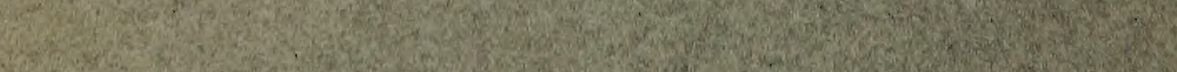
(2) 